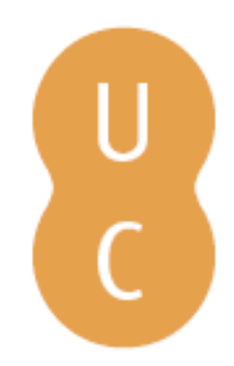

\title{
Rompalina
}

\section{Hermenêutica da facticidade: contraprojeto à fenomenologia transcendental?}

Autor(es): KahlmeyerMertens, Roberto S.

Publicado por: Imprensa da Universidade de Coimbra

URL

persistente: URI:http://hdl.handle.net/10316.2/38242

DOI: $\quad$ DOI:http://dx.doi.org/10.14195/978-989-26-1049-8

Accessed : $\quad$ 26-Apr-2023 12:04:45

A navegação consulta e descarregamento dos títulos inseridos nas Bibliotecas Digitais UC Digitalis, UC Pombalina e UC Impactum, pressupõem a aceitação plena e sem reservas dos Termos e Condições de Uso destas Bibliotecas Digitais, disponíveis em https://digitalis.uc.pt/pt-pt/termos.

Conforme exposto nos referidos Termos e Condições de Uso, o descarregamento de títulos de acesso restrito requer uma licença válida de autorização devendo o utilizador aceder ao(s) documento(s) a partir de um endereço de IP da instituição detentora da supramencionada licença.

Ao utilizador é apenas permitido o descarregamento para uso pessoal, pelo que o emprego do(s) título(s) descarregado(s) para outro fim, designadamente comercial, carece de autorização do respetivo autor ou editor da obra.

Na medida em que todas as obras da UC Digitalis se encontram protegidas pelo Código do Direito de Autor e Direitos Conexos e demais legislação aplicável, toda a cópia, parcial ou total, deste documento, nos casos em que é legalmente admitida, deverá conter ou fazer-se acompanhar por este aviso. 

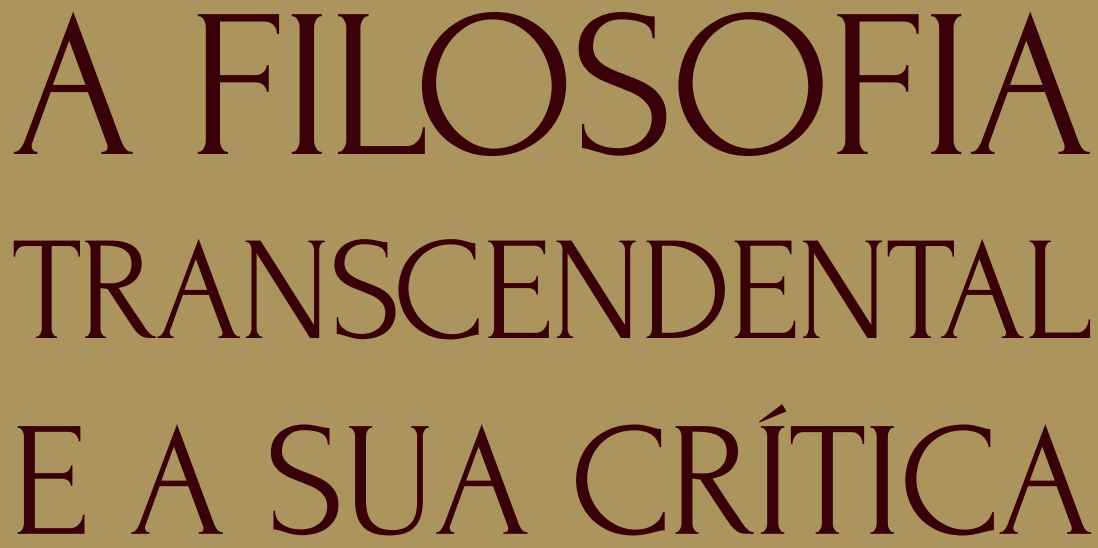

IDEALISMO • FenOMENOLOGIA • HERMENÊUTICA

\author{
DIOGO FERRER \\ LUCIANO UTTEICH \\ (COORDENADORES)
}




\title{
HERMENÊUTICA DA FACTICIDADE: CONTRAPROJETO À FENOMENOLOGIA TRANSCENDENTAL? \\ HERMENEUTICS OF FACTICITY, COUNTER-PROJECT TO THE TRANSCENDENTAL PHENOMENOLOGY?
}

Roberto S. Kahlmeyer-Mertens *

(Universidade Estadual do Oeste do Paraná - UNIOESTE)

\begin{abstract}
This chapter takes as its theme the hermeneutic phenomenology of Heidegger and their differences ahead to transcendental phenomenology. We intend to question whether Heidegger's philosophy is only one alternative to Husserl or is the opposition to this. Considering this, our most primordial objective is to point out differences between the phenomenological projects of Husserl and Heidegger's. For this purpose, we need to reconstruct, summarily, the Heidegger's phenomenology terms and indicate how it is presented face of the Husserl's phenomenology; also to characterize Heidegger's project of a hermeneutics of facticity. This characterization will introduce the fundamental concepts of
\end{abstract}

*kahlmeyermertens@gmail.com

Doutor em Filosofia pela Universidade do Estado do Rio de Janeiro - UERJ. Atualmente é Professor Adjunto na Universidade Estadual do Oeste do Paraná-UNIOESTE. Tem Graduação (Bacharelado) e Mestrado em Filosofia. Desenvolve pesquisas com ênfase em metafísica, fenomenologia e hermenêutica filosófica. Estuda o autor alemão Martin Heidegger desde o ano de 1995, tendo interesse também pela filosofia clássica alemã. 
original synthesis of Heidegger, and its phenomenological position on the Husserlian project of a perennial philosophy.

Keywords: Hermeneutic phenomenology; transcendental phenomenology; hermeneutics of facticity; perennial philosophy; Husserl; Heidegger.

Resumo: O presente capítulo assume por tema a fenomenologia hermenêutica de Heidegger e suas diferenças frente à fenomenologia transcendental de Husserl. Buscamos questionar se a filosofia de Heidegger é apenas uma alternativa à de Husserl ou se constitui um contraprojeto à outra. Tendo isso em vista, nosso objetivo mais primordial é apontar diferenças entre o projeto fenomenológico de Husserl e a fenomenologia hermenêutica de Heidegger. Para tanto, precisaremos cumprir o objetivo específico de reconstruir, de modo sumário, os termos da fenomenologia heideggeriana e indicar como ela se apresenta diante da fenomenologia husserliana; ainda, caracterizar o projeto heideggeriano de uma hermenêutica da facticidade. Essa caracterização não apenas introduz conceitos fundamentais da síntese original que é o pensamento de Heidegger, quanto seu posicionamento fenomenológico diferenciado, em nítida aproximação ao historicismo, diante do projeto husserliano de uma filosofia perene.

Palavras-Chave: Fenomenologia hermenêutica; fenomenologia transcendental; hermenêutica da facticidade; filosofia perene; Husserl; Heidegger.

A filosofia de Heidegger, especialmente a circunscrita no seu fecundo período da década de 1920, é invariavelmente apontada como "violenta". Tal reputação se deve ao confronto da tradição, atitude que, instilando crise nos conceitos filosóficos ali assentados, permitiria, além 
de um revisionismo, abordagens filosóficas originais. Essa conduta foi, em muito, responsável pela notoriedade que o jovem assistente de Edmund Husserl logrou em um período no qual a cena intelectual europeia estava dominada pelos filósofos de cátedra.

Geralmente atidos ao revisionismo drástico de Heidegger - o mesmo que programará a destruição (Destruktion) ou a desconstrução (Abbauen) da história da ontologia 428 - os intérpretes de hoje deixam de considerar o caráter conciliador do mesmo. Afinal, poucos lembram que o pensamento heideggeriano, ao se apropriar da fenomenologia madura de Husserl, acaba por associá-la ao historicismo de Dilthey, buscando neste último os subsídios hermenêuticos que faltavam no outro para pensar a objetividade histórica (fática). ${ }^{429}$ Concretamente: ao corrigir Husserl com Dilthey (procedimento para o qual vale também a recíproca), Heidegger chega, sem ter que assentir as premissas da fenomenologia husserliana ou do historicismo diltheyano (e, também, sem contrair as objeções de idealismo ou relativismo que, respectivamente, pesavam sobre esses), a um termo bastante satisfatório para o problema que conjugava as exigências de uma unidade do conhecimento teórico às de um lastro fático-histórico. ${ }^{430}$ O resultado que Heidegger aufere é um híbrido chamado "fenomenologia hermenêutica". 431

É certo que haverá críticos que, diante dessa manobra, continuarão a ver, no lugar de comunhão, o furor filosófico heideggeriano, uma vez que Heidegger faria com que aqueles autores e seus projetos o $§ 6$.

${ }^{428}$ Quanto a este projeto desconstrucionista, Cf. Heidegger (1993), especialmente

${ }^{429}$ Cf. Kahlmeyer-Mertens (2012).

${ }^{430}$ Max Scheler foi quem primeiro observou esta manobra de Heidegger. Em sua avaliação, entretanto, Scheler insere também sua filosofia na síntese heideggeriana, é o que se vê subsidiado no livro de Angelika Sander, quando a comentadora cita o autor desde seus Abhandlungen zur Philosophie, (Psychologie und Pädagogik, Bd. 240): "Em Heidegger: 'há uma união do historicismo de Dilthey com Husserl e com a minha filosofia'" (Scheler apud Sander (1996), 62).

431 Cf. Nunes (2012). 
filosóficos fossem forçados a dar mais do que se propunham. Isso se evidencia quando o elemento "fenomenológico" (componente de maior relevo naquele híbrido) entra em questão, porque, no início dos anos 20, falar em fenomenologia significa ter primeiramente a tônica husserliana em vista, e Heidegger quando vai a Husserl neste período geralmente o faz para criticar, 432 apontando inconsistências como: deixar impensado o modo de ser da intencionalidade, apoiar-se em determinações ora naturalistas e ora teóricas e, por fim, retroceder (a despeito do esforço de uma elaboração sistemática) a uma situação pré-fenomenológica ao recair no psicologismo que a própria fenomenologia sempre buscou refutar.

A partir daqui, para sondarmos a procedência dessas afirmações, precisaríamos de um movimento expositivo que nos venha assegurar uma compreensão da posição de Husserl, do teor das críticas de Heidegger e, por fim, da posição que sua hermenêutica fenomenológica ocuparia em tal cenário de ideias. Desejamos, mesmo, questionar se o projeto heideggeriano de uma hermenêutica da facticidade poderia ser considerado proposta contrária à filosofia transcendental de Husserl. Para tanto, será necessário apresentar, grosso modo, a fenomenologia transcendental de Husserl; oferecer os termos da interpretação que Heidegger faz desta; expor as linhas gerais do projeto de uma hermenêutica da facticidade.

\section{A filosofia de Husserl e a "viragem transcendental"}

Em sua situação inicial, a fenomenologia husserliana, enquanto psicologia descritiva das vivências puras, ${ }^{433}$ constitui-se a partir da

432 As cartas que Heidegger escreve a Jaspers neste período, ao exemplo, a escrita em 19/06/1923, testemunham o distanciamento das ideias de Husserl. Nesta missiva, Heidegger critica seu mestre por estar tão voltado a sua fenomenologia a ponto de desconsiderar o que ocorre no cenário acadêmico (Heidegger (2003), 32).

433 Cf. Husserl (2007). 
intencionalidade. Por definição, a intencionalidade é uma estrutura de base componente da ligação permanente entre uma figura de consciência e o fenômeno que objetivamente se lhe contrapõe. A correspondência indissociável entre esses dois relata descreve fundamentalmente a impossibilidade de atos de consciência que se façam na ausência de objetos. Da mesma maneira, este laço intencional aponta a total impossibilidade de espaços fenomenais sem a objetualidade. ${ }^{434}$

Em sua obra Investigações Lógicas (1900), Husserl indica que o conhecimento dos entes está ligado a atos da consciência fenomenológica, portanto, não resultando das representações de um sujeito relacionado com objetos exteriores. Na chave do cogitatum qua cogitatum, a fenomenologia indica que os objetos são imanentes à consciência e assim se busca reatar o élan fenomenológico da consciência com o conhecimento objetivo possível, grifando a relação intencional indicativa de que todo conhecimento é constituído em atos de conhecer, ou ainda, que todo ato de conhecer é uma objetivação do ente na medida em que ele é na consciência. ${ }^{435}$

Sem pretender, aqui, uma apresentação pormenorizada da cunhagem e desenvolvimento da concepção de intencionalidade, importa dizer que Husserl considera nesta o fato de ela propiciar clareza quanto à constituição de espaços de manifestação de fenômenos, estes que não se dão mediante representação, mas na intuição de suas idealidades, ou seja: aparecendo tal como é dado, o objeto evidencia o que há de mais essencial em si mesmo. Assim, para Husserl, o modo com que intencionalmente a consciência atua permite, verdadeiramente, a percepção dos objetos. ${ }^{436}$

Desenvolvendo fenomenologicamente a intencionalidade, Husserl passa a evidenciar que a consciência normalmente tem esta estrutura

\footnotetext{
${ }^{434}$ Cf. Husserl (2007).

435 Cf. Mohanty (2012).

436 Cf. Willard (1995).
} 
fenomenal obstruída, tomando, por conseguinte, os campos fenomenais abertos pela consciência intencional de modo simplista e ambíguo. Com a fenomenologia é possível apontar essa ambiguidade como aquilo que resulta da desconsideração reiterada do componente intencional que a fenomenologia já sempre conta. Destarte, para Husserl, a consciência em atitude natural é ingênua nos levando à convicção de que o conhecimento é constituído a partir da relação empírica de um sujeito dado a priori e dotado de aparato psíquico ante a presença efetiva dos entes. Neste caso, tanto sujeito quanto objeto derivariam de hipóstases, uma psicologista e outra realista. ${ }^{437}$ A análise fenomenológica da intencionalidade, a rigor, nos permite compreender o caráter transcendente dos atos de consciência e, desde os mesmos, os campos nos quais os fenômenos já se dão desde sempre como correlatos noemáticos à consciência. A partir daí, passa a ser possível ao método fenomenológico suspender as implicações obstrutivas e hipostasiantes da atitude natural, decompor conglomerados de atos de consciência em caracteres intencionais primitivos, descrever a essência pura e transcendental das vivências e analisar os laços necessários que a consciência possui com seus objetos. Estas são tarefas da fenomenologia de Husserl, pelo menos no âmbito de suas Investigações Lógicas. ${ }^{438}$

Na década subsequente a essa obra, Husserl se empenhará em dar desdobramentos ao seu projeto fenomenológico, os quais, para alguns, constituiriam mais a criação de uma "nova sede de sua atividade acadêmica" 439 do que apenas desenvolvimentos do programa anterior. Intentando um conhecimento indubitável, fundado na evidência de uma verdade imutável e absoluta, Husserl presume poder encontrar o fundamentum inconcussum para este na própria consciência, por isso, volta-se para uma análise da mesma. Com este movimento,

\footnotetext{
437 Cf. Lévinas (1995).

438 Cf. Mohanty (2012).

${ }^{439}$ Heidegger (2009), 90.
} 
nosso filósofo pretende não apenas descrever a economia do cogito nos atos do conhecer, quanto desvendar o modo de ser das estruturas transcendentais envolvidas na atividade descritiva própria à fenomenologia. Desta feita, aquilo que, no título de nosso tópico, chamamos de "viragem transcendental" não é outra coisa que a nova direção que Husserl dá à sua fenomenologia, um encaminhamento à "consciência transcendental" ao "ego puro" que, doravante, passaria a ser objeto dessa pesquisa, como o próprio filósofo nos permite depreender a partir de estratos de sua obra Ideias para uma Fenomenologia Pura e para uma Filosofia Fenomenológica: ${ }^{440}$

“Seguiremos nesses estudos até onde for necessário para levar a cabo a evidência que buscávamos, a saber, a evidência de que a consciência tem em si mesma um ser próprio, o qual não é atingido em sua essência própria absoluta pela exclusão fenomenológica. [...] Somente por meio dessa evidência a epoché fenomenológica merecerá seu nome, e levá-la plena e conscientemente a termo mostrar-se-á ser operação necessária que nos franqueia o acesso à consciência pura e, consequentemente, a toda região fenomenológica. [...] Motivos importantes, fundados na problemática epistemológica, justificarão que designemos a consciência "pura", da qual tanto se falará, também como consciência transcendental [...]." 441

A fenomenologia transcendental, como um exame que pretende descobrir a efetividade da consciência pura passa, assim, a ser caracterizada como uma "egologia". Husserl acredita que esta meditação fenomenológica fundamental não significa recair no âmbito de um "eu empírico" capaz de nos devolver às hipóstases psicologistas. Por isso,

440 Doravante referido com a abreviatura Ideias.

441 Husserl (2006), 84-85. 
o filósofo empreende uma fenomenologia transcendental, por entender ser esta a maneira mais genuína de se fazer filosofia fenomenológica. Por isso afirma, no conhecido verbete "fenomenologia" da Encyclopædia Britannica, que "o destino da filosofia científica depende de uma superação radical de todo psicologismo, que não só revele o contra-senso de princípio, mas também satisfaça a seu núcleo de verdade transcendentalmente significativo". ${ }^{442}$ É possível perceber que a philosophia transcendentalis de Husserl (na medida em que se empenha em buscar a verdade do conhecimento em substâncias inalteráveis e eternas, para além do particular da historicidade) almeja a uma philosophia perennis.

Em sua época, o novo projeto husserliano demorou a ser assimilado pelas figuras atuantes na cena filosófica (o próprio Heidegger confessa só ter compreendido plenamente os termos dessa nova filosofia após passar a conviver no estreito círculo de relacionamento de Husserl, portanto, em contato direto com o "iniciador" da fenomenologia). ${ }_{4}^{44}$ Ora, se a filosofia pura das Ideias (em 1910-13), de início, foi motivo de incompreensão, é durante a redação conjunta do citado verbete para a referida enciclopédia (em 1925) que ficam flagrantes as divergências de compreensão entre Husserl e Heidegger acerca de seu caráter e propósito. É o que se pode depreender a partir dessa passagem:

“A «fenomenologia pura»é a «ciência básica» da filosofia por ela marcada. «Pura» significa: «fenomenologia transcendental». «Transcendental» é a «subjetividade» do sujeito que conhece, age e valora. Ambos os títulos «subjetividade» e «transcendental» indicam que a «Fenomenologia» se encaminhava, consciente e decididamente, na esteira da tradição da filosofia moderna [...]." 444

\footnotetext{
442 Husserl (1952), 701.

443 Heidegger (2009), 88.

${ }^{444}$ Heidegger (2009), 88.
} 
Com clareza inabitual, Heidegger nos diz ser um erro insistir em uma filosofia transcendental, mesmo que esta possuísse acento fenomenológico, isso porque, se formos fiéis aos princípios metódicos da fenomenologia firmados pelo próprio Husserl, conservar a subjetividade (ainda que refinadamente tratada como ego puro) é expor-nos ao risco da concepção tradicional de sujeito realocar-se sub-repticiamente nessa, de modo que seria possível indicar que, na fenomenologia de Husserl, esta noção reteria ainda um resquício subjetivo. ${ }^{445}$ Isso significa ainda contar com pressupostos com os quais se julgava estruturar metafisicamente o real, do mesmo modo, arrolar elementos que nos colocariam novamente diante de tendências teórico-hipostasiantes que, inevitavelmente, acarretam crises. ${ }^{446}$

Sem aderir aos novos rumos da fenomenologia de Husserl (como também depois fizeram Landgrebe, Löwith e Fink), Heidegger compreende que mais importante do que se ocupar da gênese e das operações transcendentais de uma subjetividade sintetizadora de vivências seria compreender as ligações de sentido que denotam a implicação entre o pólo equivalente à consciência e seus correlatos. Assim, entrevendo a necessidade de radicalizar a descoberta da intencionalidade, Heidegger passa a tematizar a ligação desta estrutura na relação com os fenômenos, na medida em que esses se evidenciam à consciência em atitude fenomenológica. A fenomenologia pode aqui deslindar a malha de referências que esse ente possui junto aos demais e o caráter factual que lhe é próprio. ${ }^{447}$

\section{De uma hermenêutica da vida fática: caracterização do projeto}

É nesse contexto que a facticidade se torna temática da fenomenologia. Para Heidegger, facticidade denotaria o modo de ser de nossa

\footnotetext{
445 Cf. Heidegger (2009).

446 Cf. Szilasi (1973).

447 Cf. Szilasi (1973).
} 
existência, maneira que se expressa sempre e a cada vez aí, na ocasionalidade (Jeweiligkeit) do mundo. Tal concepção (quase onipresente no pensamento do jovem Heidegger) diz respeito, nessa fase, ao modo com o qual os entes são compreendidos como significativamente entes, e às posturas e comportamentos possíveis em um horizonte de significado. Ao ocupar-se da facticidade, Heidegger a aborda em vista do horizonte intencional constituinte do campo de manifestação dos fenômenos, para, assim, possibilitar pensar as significações historicamente consolidadas do mundo por meio da fenomenologia.

O empenho heideggeriano por compreender a facticidade é o que motivará a sua hermenêutica fenomenológica da facticidade. ${ }^{448}$ Essa interpretação tratará, a princípio, dos campos objetuais intencionalmente abertos em que se dão modos de relação nos quais os entes não se mostram apenas como dados de antemão, mas como à mão para $o$ uso. É seguindo as indicações da lida prática que se torna possível um movimento de descrição e análise desses campos de uso, que remontam ao mundo como horizonte de manifestação possível dos entes. Isso quer dizer que a hermenêutica da facticidade investiga o modo como vivemos e pensamos junto aos entes, já sempre orientados pelo sentido que o caráter de fato dos mesmos nos fornece.

Logo em seguida, essa mesma investigação passa a descrever o modo com que nos movimentamos desde sempre em meio a este conjunto de significações consolidadas; a maneira com a qual, nestes contextos de significação, nos ocupamos com problemas e lhes apresentamos soluções; o modo com o qual, com uma semântica his-

\footnotetext{
$448 \mathrm{O}$ projeto de uma hermenêutica da facticidade (cujos resultados foram originalmente apresentados na forma de uma preleção didática intitulada Ontologia - Hermenêutica da Facticidade, proferida na Universidade de Friburgo em 1923 e publicada em 1984 sob o mesmo título), embora proporcionalmente pouco conhecido do público filosófico, é crucial para compreender o pensamento do Heidegger da década de 1920, especialmente por lançar luz sobre muitos pontos sobre a obra Ser e Tempo (1927). A relevância dessa preleção está em ela favorecer a compreensão de muitos pontos relacionados àquilo que posteriormente veremos o filósofo nomear de analítica existencial e, de modo mais específico, ao fenômeno no foco desta análise fenomenológica: o "ser-aí" (Dasein).
} 
toricamente estabelecida, interpretamos a nós mesmos e aos demais entes e perguntamos com pretensões filosóficas sobre o nosso ser e sobre o ser dos entes que nos cercam.

Tomando estritamente, uma hermenêutica da facticidade vem evidenciar que o ser-aí já nasceu e se criou segundo interpretações vigentes e por ele irrefletidamente assumidas. Assim, o ser-aí compreende a si e a tudo segundo a experiência das concepções tradicionais. Essa compreensão revela e orienta suas reais possibilidades, o que significa que o ser-aí (bem como seus contemporâneos) parece já ter seu destino preparado por interpretações prévias que, de início e na maior parte das vezes, determinam sua forma de pensar e agir. 449 Heidegger esclarece esse traço característico da facticidade do ser-aí, acenando para o fato de que, ao herdar as interpretações tradicionais, mesmo este modo de perguntar (bem como as maneiras com as quais tal questão se entabula) segue significados estabelecidos faticamente. Tal modo de questionar, herdado das diversas iniciativas de pensamentos anteriores, nos é transmitido na forma de compreensões reduzidas que nos fornecem rotas que se tornaram tradicionais, nas quais encaminharíamos nossas interpretações. Neste modo de interpretar cotidiano, mesmo nosso ser-aí se revela como aquele que se vê desde compreensões simplificadas, ou ainda, "encurtadas" da facticidade:

“A manifestação mais inequívoca desta característica ontológica se evidencia na tendência da vida fática (facticidade) simplificar as coisas. Nesta dificuldade de fazer-se a cargo de si mesma, torna-se patente que a vida - conforme o sentido fundamental de seu ser e não em sentido de uma propriedade acidental - é um fenômeno realmente complexo. Se a vida fática é propriamente a que é neste tipo de existência complexa e difícil de assumir, então o modo verdadeiramente adequado

449 Cf. Heidegger (1988). 
de aceder a ela e de manter aberto este acesso só pode consistir em reconhecer essa pesada carga que arrasta a vida." 450

Como se vê, a hermenêutica fenomenológica é capaz de esclarecer que mesmo as posições filosóficas julgadas duradouras assentam em estruturas prévias determinantes das significações fáticas dos entes no mundo. Isso nos legitima a afirmação de que até o pensamento metafísico, consignado na "história da filosofia", encontra-se lastreado na facticidade; afinal, também a metafísica partiria de posições, visões e concepções condizentes com significados de um determinado mundo, este que, da maneira com que está consolidado, só faculta trânsito no interior das compreensões tradicionais (o que representaria um embotamento da compreensão dos entes como fenomenalmente se mostram).

Hermenêutica da facticidade nomeia, portanto, o esforço por delimitar um solo no qual o filosofar tem lugar sem arrolar uma cadeia de preconcepções da facticidade tradicional, isto é: ela busca interpretar a existência complexa da facticidade, de modo a esclarecer a sua objetividade específica (libertando-a das autointerpretações simplistas efetuadas a partir do que herda) e o escopo da referida hermenêutica. Tem, adicionalmente, a tarefa de interpretar originariamente a vida fáctica, sendo, pois, uma análise que a facticidade faz de si mesma. ${ }^{451}$ Assim, "Hermenêutica da facticidade é uma realização insigne da própria facticidade; ela é a clarificação expressa de um ser que é em si clarificado [...]". ${ }^{452}$ Numa palavra, a hermenêutica da facticidade busca clarificar o que, na existência fática do ser-aí, lhe fora apenas legado, e o que nela permanece irrefletido, para, então, trazer compreensivamente tudo o quanto for fático ao nível de sua compreensão, grifando as articulações que este ente tem com o ser. Nas palavras do filósofo:

\footnotetext{
450 Heidegger (1976), 19.

451 Cf. Gadamer (1976).

452 Figal (2007), 23.
} 
"A hermenêutica tem o trabalho de fazer a existência própria de cada momento acessível em seu caráter de ser à existência mesma, de comunicá-la, de clarificar o distanciamento de si mesmo que afeta a existência. Na hermenêutica se configura a possibilidade de chegar a compreender-se e de ser este que compreende. [...] A interpretação é algo cujo ser é do próprio viver fático. Se chamarmos, ainda que impropriamente, a facticidade de "objeto" da hermenêutica [...] diremos que esta, a hermenêutica, estaria assim em seu próprio objeto." 453

Para uma investigação que visa o sentido do ser, tendo a facticidade diante de si, não se pode prescindir das posições, da conceptualidade e dos sentidos prévios das interpretações legadas acerca do ser. Contudo, isso não significa que a hermenêutica da facticidade simplesmente tomaria para si uma dessas interpretações sedimentadas tais como consignadas tradicionalmente; fizesse isso, permaneceria movendo-se nos circuitos que a metafísica engendrou historicamente em seu esforço por tornar pensável o ser. Deste modo, ao invés de um posicionamento propício a uma interpretação do sentido do ser, nos veríamos aderidos a uma das muitas correntes de interpretação do problema ontológico, i.e., nos submeteríamos (ainda que não tivéssemos exata clareza sobre isso) ao cânon interpretativo de certa ontologia, seja ela a antiga, a medieval ou a moderna.

Não é segredo que - desde o início - Heidegger tenha a questão do ser como o escopo mais primordial de suas investigações filosóficas. ${ }^{454}$ Somando esforços na execução do que mais tarde se chamará

${ }^{453}$ Heidegger (1988), 15.

454 A questão do ser interessa ao filósofo desde 1907. O próprio autor reconhece que esta se faz presente desde suas primeiras e "desajeitadas tentativas para penetrar na filosofia" (Heidegger (2009), 85), ajudadas pelo livro de Brentano sobre Aristóteles. Essa questão, entendida como "a mais primordial e concreta entre todas" (Heidegger (1993), 12), reincide, ora direta, ora indiretamente, como problema nos trabalhos que documentam a primeira fase de seu pensamento. Com a fenomenologia, Heidegger 
de "ontologia fundamental", a hermenêutica da facticidade não apenas colaborará na definição da situação da filosofia atual, quanto será o primeiro passo de Heidegger no sentido de compreender o caráter ontológico da vida fática na articulação com a questão do ser. Nosso filósofo aposta na facticidade, a qual expressa a nossa determinação mais própria "em cada ocasião [...], na medida em que é «aì no tocante ao nosso ser". 455

Com essa hermenêutica do aí (ainda menos do que será o projeto da analítica existencial), Heidegger traça o caminho que sua filosofia deveria trilhar para a recolocação da pergunta pelo ser. 456 Tal fenomenologia hermenêutica se justifica por indicar à ontologia fundamental de qual ente deve partir a pergunta ontológica. O ente em questão seria o único capaz de compreender o sentido do ser, isto é: o ente para o qual o ser dispõe seu sentido; o ente para o qual, em sua existência fática, o ser se lhe pode apresentar como questão. ${ }^{457}$ O ente que possui o privilégio ontológico de compreender e questionar o ser é designado por Heidegger ser-aí (Dasein). ${ }^{458}$

A descrição fenomenológica das estruturas existenciais do ser-aí, elaborada na forma de uma analítica existencial, em Ser e Tempo (1927), é o que viabiliza a empresa da ontologia fundamental. Ressalte-se,

reforça a posição, galgada em seus estudos de lógica desenvolvidos na década de 1910, segundo a qual a retomada da questão ontológica não se efetiva por uma abordagem meramente lógica de temas e problemas. Heidegger sabe que um acesso revitalizante à metafísica não ocorreria trilhando a via crítica reaberta pelo neokantismo, que propunha reformá-la a partir de seus próprios expedientes. O filósofo aposta na fenomenologia como meio de garantir a recolocação da pergunta acerca do ser, no seu caso, agindo diferentemente da tradição. Assim, Heidegger não desenvolve uma nova teoria sobre a essência do ser, não perscruta supostas propriedades de um ser tratado objetivamente, tampouco transige com modelos teóricos usados pela metafísica para desse tratar. $\mathrm{Na}$ ontologia fundamental de Ser e Tempo, o que está em questão é o sentido do ser.

455 Heidegger (1988), 7.

456 O leitor poderá perceber, desde este ponto, o quanto a ideia de fático é influente na cunhagem e aplicação do termo ser-aí (Dasein), indicando na essência do humano justamente a ocasionalidade expressa no prefixo -aí (Da-).

\footnotetext{
457 Cf. Heidegger (1993).

458 Heidegger (1993), 12.
} 
todavia, que a referida análise está ligada a dois outros contrafortes da ontologia em questão, a saber: a destruição da história da ontologia (operação heideggeriana que pretende recondicionar a maneira com que o ser fora interpretado historicamente) e a hermenêutica da facticidade, como se poderia presumir após sua concisa exposição, movimento que acentuou sua importância.

\section{A ontologia entre o transcendental e o existencial-fático}

Vimos que a ontologia fundamental passa pela interpretação da vida fática, esta tomada por Heidegger na chave da intencionalidade e, portanto, em moldes estritamente fenomenológicos. Heidegger, após ter definido a situação hermenêutica da ontologia contemporânea, está convicto de que: "somente com a fenomenologia surge um conceito adequado para a investigação ontológica". ${ }^{459}$ A vinculação com a fenomenologia, entretanto, não impede o filósofo de demarcar as diferenças do seu pensamento ante o de Husserl, distinção que ficará mais bem acentuada se recorrermos à preleção Ontologia Hermenêutica da Facticidade.

Heidegger considera que uma fenomenologia transcendental (como a que Husserl propugna para buscar um fundamento ontológico absolutamente seguro para verdadeiramente basear uma construção filosófica sólida) ainda conserva impensado o teor deste "transcendental" expondo-se, portanto, ao risco dessa reflexão incorrer em premissas idealistas "enquanto este não passar por uma elucidação prévia de sua determinação ontológica fundamental". ${ }^{460}$ Para a ontologia de Husserl, todavia, pensar o modo de ser do transcendental como sendo o ser-aí seria não apenas desnecessário quanto irrelevante,

459 Heidegger (1988), 2.

460 Heidegger (1993), p.46. 
posto que, como já se disse, a egologia fenomenológica husserliana privilegia o cogitatum, de sorte que, para esta, também o ser-aí seria um cogitatum e apenas assim tal ente importaria. ${ }^{461}$

Malgrado as diferenças frente a Husserl, a ontologia de Heidegger (e, por conseguinte, a analítica existencial que conduz a essa) deixa transparecer a influência das Investigações Lógicas de Husserl (mesmo após a síntese crítica elaborada por Heidegger), afinal é o implemento fenomenológico que dá à ontologia de Heidegger caráter fundamental. Tal predicado se justifica pelo fato de este ainda levar em conta o princípio da intencionalidade, cujo alcance permite relacionar o ser aos campos objetivos intencionalmente constituídos, universo de condições do encontro com os entes (como possível a partir da fenomenologia de Husserl). Contudo, com Heidegger, tal estrutura aparece imersa no domínio originário da existência, ou seja: a intencionalidade agora também aponta ao ser-aí, ente que decide sua própria condição ontológica ao existir.

Além da intencionalidade, outro traço da fenomenologia de Husserl é aproveitado pelo projeto filosófico de Heidegger (em especial na hermenêutica da facticidade e na analítica existencial), trata-se da epoché. Com este gesto inaugural, decisivo e contínuo, a fenomenologia põe em suspenso a validade de conteúdos das duas referidas tendências teórico-hipostasiantes. Recorrendo a este componente do método fenomenológico em favor de seus propósitos filosóficos, Heidegger não hesita submeter à epoché a consciência transcendental que Husserl tem em vista em seu Ideias. ${ }^{462}$ Assim:

“[...] o jovem Heidegger desenvolveu a sua hermenêutica da facticidade contra Husserl, mas não abdicou, nesse caso, do pensamento da epoché. $\mathrm{O}$ «retorno desconstrutivo às fontes originárias dos motivos» pressupõe epoché; ela é inserida

461 Szilasi (1973), 84.

462 Cf. Nunes (2012). 
na «facticidade» do ser-aí e, de maneira correspondente, na «intuição hermenêutica» enquanto o autopresente conceitualmente articulável do ser-aí." 463

A epoché operada por Heidegger alveja em cheio a concepção transcendental de ego ao identificar nele qualidades subjetivas residuais passíveis de lhe serem apontadas ainda determinações metafísicas do ente que caracterizamos como ser-aí (como possuía o sujeito transcendental da filosofia moderna junto a um Descartes e a um Kant). ${ }^{464}$ O efeito da epoché fenomenológica, assim, põe "entre parênteses" mesmo a validade da consciência (ego, cogito) transcendental, revertendo o efeito da epoché contra a fenomenologia de Husserl. Desse modo:

"De maneira inequívoca, Heidegger coloca a sua compreensão da hermenêutica em contraste com a compreensão husserliana da fenomenologia; [...] Desde que a hermenêutica entra em jogo no jovem Heidegger, ela é pensada como um contraprojeto em relação à fenomenologia de matiz husserliano." 465

Husserl, por sua vez, quando toma ciência desses encaminhamentos do jovem Heidegger (elaborados desde 1923, mas apenas divulgados no conjunto de Ser e Tempo em 1927), logo compreende a hermenêutica-fenomenológica como o tal contraprojeto à sua própria filosofia e, ao conhecer completamente o saldo das interpretações heideggerianas, Husserl objeta veementemente argumentando ser uma incoerência tentar colocar a consciência sob o efeito da epoché, já que,

463 Figal (2007), 28. Não apenas Figal (2007) é desta opinião, também Gadamer (1976) designará a hermenêutica da facticidade como uma virada decisiva de Heidegger contra a fenomenologia de Husserl.

464 Cf. Nunes (2012).

465 Figal (2007), 23. 
para ele, o ego transcendental seria irredutível ao dito procedimento. Num segundo momento, Husserl acusa, com extrema incisividade, Heidegger de tentar "transpor ou fazer passar a clarificação fenomenológica constitutiva de todas as regiões do ente, e do universal, à região total do 'mundo' sobre o plano antropológico; assim, toda a problemática é uma transposição [Übertragung]: o ser-aí corresponde ao ego, etc". 466 Heidegger rechaçou, por mais de uma vez, esta interpretação que fora, de certa maneira, comum à primeira recepção de Ser e Tempo ${ }^{467}$ ressaltando que, em sua nova e radicalmente inexcedível cunhagem fenomenológica, o ser-aí não é um símile da consciência ou, quem sabe, outro nome para se referir à mesma: tratar-se-ia de um ente pensado num contexto radicalmente diverso do antropológico e mesmo do transcendental.

Ora, não sendo o ser-aí um correspondente do ego, aonde chega, então, a investigação heideggeriana? A epoché estendida à consciência põe-nos diante da expressão do ser-aí como um poder-ser. ${ }^{468}$ Dizer que o tal ente pode ser não significa que ele tenha possibilidades. Heidegger nos assegura que "ele não 'tem' a possibilidade apenas como uma propriedade simplesmente dada." 469 Desta feita, apenas se entendêssemos as possibilidades como recursos contingenciais dispostos como em um rol para uso do ser-aí, encontraríamos este como figura substancial que assumiria eventualmente uma ou outra dessas possibilidades; do mesmo modo, apenas pensando o poder-ser como um silo abastecido de possibilidades com as quais o ser-aí se revestiria ocasionalmente, teríamos possibilidades ônticas. Essas duas interpretações não traduzem o modo de ser do ente que somos, como Heidegger nos faculta dizer:

\footnotetext{
466 Husserl (1993), 14.

467 Cf. Heidegger (2009).

468 Cf. Nunes (2012).

469 Heidegger (1993), 43.
} 
"Ser-aí não é um simplesmente dado que tem, adicionalmente, o poder de ser alguma coisa. Ele, primariamente, é possibilidade de ser. Cada ser-aí é o que pode e o como pode-ser possível. A possibilidade essencial do ser-aí pertence a modos característicos de ocupação no "mundo", de preocupação pelo outro e, nisso tudo, o já sempre poder-ser si mesmo. O poder-ser existencial de cada ser-aí difere sempre da possibilidade lógica vazia como a contingência de um ente simplesmente dado, com o qual isto ou aquilo pode se «passar». Como categoria modal do simplesmente dado, a possibilidade significa o ainda não real e o nem sempre necessário. Ela caracteriza o apenas possível." 470

O poder-ser é possibilidade primordial do ser-aí, constituindo, assim, não só a primeira, mas sua "determinação mais originária e mais positiva". ${ }^{471}$ Somente por ser fundamentalmente poder-ser é que o ser-aí é possível. Afirmações como essas realçam a diferença do ente que compreende o ser frente aos demais que simplesmente são (inclusive o sujeito com estruturas transcendentalmente dadas); reforçam, também, o fato de esse ente ter compreensão de ser e, por conseguinte, compreender o modo de seu próprio ser. Ora, compreender o próprio ser é um modo de, sendo, relacionar-se com o mesmo, e é antes por isso (e não por algum traço subjetivo) que "o ser-aí se constitui pelo caráter de ser meu, segundo este ou aquele modo de ser". ${ }^{472}$ Podendo ser, as possibilidades concretas de ser do ser-aí são conjugadas.

O movimento de exposição até aqui (inclusive a digressão que nos aproximou da temática de Ser e Tempo) nos mostrou que o programa filosófico de uma hermenêutica da facticidade faz da fenomenologia

\footnotetext{
470 Heidegger (1993), 143.

471 Heidegger (1993), 144.

472 Heidegger (1993), 43.
} 
mais do que um exame do puro cogito enquanto constituição essencial de uma universalidade. Ao opor-se violentamente a uma egologia transcendental, Heidegger vai buscar a base ontológica ao conhecimento dos entes no próprio ser-aí; antes, assegurando-se da autotransparência deste ente por meio da análise de sua facticidade, uma vez que tal existir é o que define o ente que somos na existência, bem como o modo com que lidamos com os sentidos e significados próprios a esta.

\section{Conclusões}

Partindo de considerações sobre a meditação fenomenológica fundamental de Husserl, pretendemos mostrar que, para este, sua fenomenologia transcendental não significa uma recaída no psicologismo. Detivemo-nos, também, na interpretação que Heidegger faz dessa filosofia e da indicação do quanto, para ele, seria problemática uma investida (mesmo pretensamente fenomenológica) ao terreno transcendental. Para Heidegger, ao respeitarmos os princípios do método fenomenológico, seria impossível subscrever o posicionamento de Husserl sem gravíssimas reservas, isso porque, volver-se ao transcendental seria ainda conservar o caráter subjetivo da consciência. Assim, Heidegger interpreta que uma fenomenologia transcendental, em sua busca por um fundamento ontológico absolutamente seguro para verdadeiramente basear uma construção filosófica sólida, deveria, antes de mais, questionar o caráter "transcendental" da consciência, tornando sua determinação ontológica transparente a ela.

De modo análogo, Heidegger pretende tomar sobre a pedra-de-toque da filosofia a essência da consciência, mas, antes, compreende que uma análise do estado de fato desta se faz urgente. Ao se conservar atento aos achados fenomenológicos possibilitados a partir de uma lida radicalizada com a estrutura de base da intencionalidade, Heidegger não apenas desenvolve uma filosofia fenomenológica, quanto 
também uma fenomenologia hermenêutica. O olhar interpretativo dessa abordagem fenomenológica pousaria, assim, sobre a facticidade. Essa estrutura existencial (facticidade) denotaria o modo de ser do ente que ocasionalmente somos, o mesmo ente que (assim dirá Heidegger em Ser e Tempo) responde pela compreensão do sentido do ser e por seu questionamento. A ocasionalidade fática do ser-aí que somos é tema de uma hermenêutica da facticidade, com a qual Heidegger evidencia que o ser-aí existe e se interpreta diante de sentidos, significados e tendências de interpretações que o dirigem em seu ser-no-mundo.

A hermenêutica da vida fática ensina, portanto, que mesmo quando o ser-aí reflete sobre seu mundo, inclusive no momento em que, especificamente, faz filosofia, interpretações consolidadas em uma determinada facticidade nos antecedem e orientam seus modos de se comportar prática e teoricamente. No caso do filosofar, muitas dessas orientações seriam oriundas de uma tradição secularmente estabelecida; desta feita, a hermenêutica da facticidade designa o esforço por esclarecer um espaço interpretativo que não traga consigo um conjunto de preconceitos filosóficos da tradição. A hermenêutica do aí, a bem dizer uma antessala da ontologia fundamental heideggeriana delineia a rota que a filosofia precisaria seguir para a questão que Heidegger considera a mais importante: a pergunta pelo ser.

Embora a questão do ser, no presente estudo, compareça apenas no pano de fundo de nossa temática, não deixa de ser significativo o fato de que é em seu propósito que Heidegger desenvolve a sua interpretação da facticidade (e não apenas esta, recordemos, também, dos projetos de uma destruição da história da ontologia e da analítica existencial). Esta análise interpretativa do fático evidenciaria a impossibilidade de uma filosofia perene, e, por sua vez, a necessidade de levar em conta posições prévias da facticidade (historicidade) para que uma ontologia fundamental possa ser levada a efeito.

Por mais que apreciemos o quanto Heidegger confronta indiscutivelmente a filosofia de Husserl, é digno de nota (não obstante 
diferenças específicas que aparecem nesta caracterização) que o jovem filósofo, neste período, ainda pensa como um fenomenólogo, revelando ainda alguma influência de seu mestre (especialmente os saudáveis influxos vindos das Investigações Lógicas, como vimos). A apropriação da intencionalidade e a utilização da redução fenomenológica (em especial a epoché), entretanto, levam Heidegger a resultados bastante diversos dos de Husserl. Ao chegar ao ser-aí, enquanto expressão paradigmática da essência do humano, Heidegger não tem em vista um modo diferente de tratar a consciência ou uma nova terminologia para a mesma. Nosso filósofo pensa ter chegado a um ente originário que preenche a qualificação de sintônico ao ser (fornecendo, inclusive, meios para questioná-lo) sem ter que transigir com a fenomenologia transcendental husserliana que, para esse, ainda significa cultivar a subjetividade nos moldes da filosofia moderna, semelhantemente ao que teríamos em Descartes e em Kant, por exemplo.

Após analisar brevemente as ideias de Husserl e algumas das objeções de Heidegger à fenomenologia transcendental, é possível asseverar - em resposta ao problema levantado em nosso capítulo que o projeto fenomenológico de uma hermenêutica da facticidade, tal como proposto por Heidegger, constituiria, sem dar vez à dúvida, um contraprojeto e mesmo uma alternativa filosófica à fenomenológica de seu mestre.

\section{Bibliografia}

FIGAL, Günter (2007): Oposicionalidade - O Elemento Hermenêutico e a Filosofia. Trad. Marco Antonio Casanova. Petrópolis, Vozes.

GADAMER, Hans-Georg (1976): "Un écrit 'théologique' de jeunesse". In: Heidegger, Martin: Interprétations phénoménologiques d'Aristóteles. Trad. J-F Courtine. Paris, T.E.R. (edição bilíngue, alemão-francês), pp. 9-15.

HEIDEGGER, Martin (1976): Interprétations phénoménologiques d'Aristóteles. Trad. J-F Courtine. Paris, T.E.R. (edição bilíngue, alemão-francês).

HEIDEGGER, Martin (1988): Ontologie: Hermeneutik der Faktizität. In: Gesamtausgabe II. Abteilung: Vorlesungen. Band 63. Frankfurt am Main, Vittorio Klostermann. 
HEIDEGGER, Martin (2009): "Meu Caminho para a Fenomenologia". In: Sobre a Questão do Pensamento. Trad. Ernildo Stein. Petrópolis, Vozes, pp.85-93.

HeIDEGGER, Martin (1993): Sein und Zeit. 17. ed. Tübingen, Max Niemeyer.

HEIDEGGER, Martin - Jaspers, Karl. (2003): Correspondencia (1920-1963). Trad. Juan José Garcia Norro. Madrid, Síntesis.

HUSSERL, Edmund (2006): Ideias para uma Fenomenologia Pura e para uma Filosofia Fenomenológica. Trad. Marcio Suzuki. Aparecida, Ideias \& Letras.

HUSSERL, Edmund (2007): Investigações Lógicas: Investigações para a Fenomenologia e a Teoria do Conhecimento. Vol.II. Trad. Pedro M. S. Alves; Carlos Aurélio Morujão. Lisboa, Centro de Filosofia da Universidade de Lisboa.

HUSSERL, Edmund (1974): Ideen zu einer reinen Phänomenologie und phänomenologischen Philosophie. In: Husserliana: Edmund Husserl Gesammelte Werke. Band. III. (Org.): Walter Biemel. Haag, Martius Nijhoff.

HUSSERL, Edmund (1952): "Phenomenology". In: Encyclopædia Britannica. 1952. v. XVII, p. 701.

HUSSERL, Edmund (1993): Notes sur Heidegger. Trad. Natalie Depraz. Paris, Les éditions de minuit.

KAHLMEYER-MERTENS, Roberto Saraiva (2012): "Wilhelm Dilthey nos Limites da Hermenêutica Clássica e Filosófica". In: Revista Portuguesa de Filosofia. nº. 68, v. 1-2. (Org.): Álvaro Balsas, pp.189-204.

LÉVINAS, Emmanuel (1995): Descobrindo a Existência com Husserl e Heidegger. Trad. Fernanda Oliveira. Lisboa, Instituto Piaget.

MOHANTY, Jitendra Nath (2012): “Intencionalidade". In: Fenomenologia e Existencialismo. Org. Hubert L. Dreyfus - Mark A. Wrathall. Trad. Cecília Camargo Bartalotti Luciana Pudenzi. São Paulo, Loyola. pp. 75-82.

MOHANTY, Jitendra Nath (1995): “The Development of Husserl's Thought". In: Cambridge Companion to Husserl. Org. Barry Smith - David Woodruff Smith. New York, Cambridge University Press, pp. 45-77.

NUnes, Benedito (2012): Passagem para o Poético. Filosofia e Poesia em Heidegger. São Paulo, Loyola.

SANDER, Angelika (1996): Mensch - Subjekt - Person: die Dezentrierung des Subjekts in der Philosophie Max Schelers. Bonn, Bouvier.

SZILASI, Wilhelm (1973): Introducción a la fenomenologia de Husserl. Trad. Ricardo Maliandi. Buenos Aires, Amorrotu.

WILlARD, Dallas (1995): "Knowledge". In: Cambridge Companion to Husserl. Org. Barry Smith - David Woodruff Smith. New York, Cambridge University Press, pp. 138-167. 
